\section{A RACIONALIDADE BIOMÉDICA DESPORTIVA E A MATERIALIZAÇÃO DO FAZER CIENTÍFICO NA MATRIZ CURRICULAR DO CURSO DE EDUCAÇÃO FÍSICA DA UFRGS}

\author{
SPORTING BIOMEDICAL RATIONALITY AND MATERIALIZATION OF SCIENTIFIC \\ PRACTICE AT UFRGS'S PHYSICAL EDUCATION SCHOOL
}

\author{
LA RACIONALIDAD BIOMÉDICA DEPORTIVA Y LA MATERIALIZACIÓN DEL \\ QUEHACER CIENTÍFICO EN LA MATRIZ CURRICULAR DEL CURSO DEL \\ EDUCACIÓN FÍSICA DE LA UNIVERSIDAD FEDERAL DE RIO GRANDE DO SUL
}

\section{Cibele Biehl Bossle*, Alex Branco Fraga*}

Keywords Physical Education and Training.

Qualitative research. Qualitative Analysis.

Palabras clave Educación Física y Entrenamiento. Investigación Cualitativa. Análisis Cualitativo.
Resumo: Este estudo de cunho qualitativo objetivou compreender as condições de possibilidade para a materialização do "fazer científico" na matriz curricular do curso de Educação Física (EF) da EsEFID/UFRGS. A literatura sobre o processo de cientifização da $E F$, assentado em uma racionalidade biomédica, e os documentos prospectados na própria instituição constituíram, respectivamente, a teoria e a empiria do estudo. Para apreciação dos documentos foi utilizada a análise documental, apoiada nas orientações de André Cellard (2012). A análise do marco documental empírico permitiu visualizar na micropolítica desta instituição específica o movimento macropolítico de cientifização da $\mathrm{EF}$, demarcado pelo declínio de um modelo técnico-esportivo e pela assunção de uma racionalidade biomédica desportiva no perfil formativo da área.

Abstract: This qualitative study aimed at understanding the conditions for "scientific practice" under the Physical Education Curriculum at EsEFID/UFRGS. Literature on the process of scientificization of $\mathrm{PE}$, based on biomedical rationality and the documents prospected at the institution itself, were the study's theoretical and empirical basis. Documents were examined based on documental analysis according to André Cellard's views. The analysis of the empirical document framework allowed us to see in the micropolitics of that specific institution the macropolitical movement of sientificization of $\mathrm{PE}$, marked by the decay of a technical-sporting model and the rise of sporting biomedical rationality in the area's educational profile.

Resumen: Este estudio de cuño cualitativo tiene como objetivo comprender las condiciones de posibilidad para la materialización del "quehacer científico" en la matriz curricular del curso de Educación Física (EF) de la EsEFID/UFRGS. La literatura acerca del proceso de cientifización de la EF, asentado en una racionalidad biomédica, y los documentos prospectados en la propia institución, constituyeron, respectivamente, lo teórico y lo empírico del estudio. Para la apreciación de los documentos fue utilizado el análisis documental, apoyado en las orientaciones de André Cellard (2012). El análisis del marco documental empírico, permitió visualizar en la micropolítica de esta institución específica el movimiento macropolítico de cientifización de la EF, demarcado por la decadencia de un modelo técnico-deportivo y por el surgimiento de una racionalidad biomédica deportiva en el perfil formativo del área.
* Universidade Federal do Rio Grande do Sul. Porto Alegre, RS, Brasil. E-mail: cibele.bossle@terra.com.br

Recebido em: 18-04-2015 Aprovado em: 13-01-2016 (c) (1) (8) Licence 


\section{INTRODUÇÃO}

Pelo menos desde o início da década de 1990 no Brasil, a pesquisa de caráter científico tem sido o ponto de convergência do trabalho acadêmico na pós-graduação em Educação Física, e, mais recentemente, muito em função do apelo às publicações em larga escala, passou a ocupar um lugar de destaque na formação inicial. Dada a sua importância, o "fazer científico" (BRACHT, 2013) tem se materializado no âmbito da formação inicial em Educação Física (EF) por meio de projetos de iniciação científica, bolsas de iniciação científica, trabalhos de conclusão de curso e artigos/capítulos de livro que contam com a autoria de estudantes da graduação (LOVISOLO, 2003; BOTELHO; OLIVEIRA, 2006; VAZ, 2008).

Para Bracht (2013, p. 19), é no período compreendido entre 1970 e 1990 que a EF se configura como um campo acadêmico no qual o "'fazer científico' (não apenas o saber científico) passa a ser parte desse campo de forma mais intensa e estrutural". Em uma análise macro, Bracht (2013) destaca, dentre os diversos fatores que impulsionaram o (e levaram à incorporação do) "fazer científico" no campo da EF, o Diagnóstico da Educação Física/Desportos no Brasil, a implantação de laboratórios de fisiologia do exercício, o desenvolvimento das Ciências do Esporte, a participação da EF no sistema de pós-graduação brasileiro, a presença e inserção da EF nas universidades.

Mazo (2000d), por sua vez, explica que o Diagnóstico da Educação Física/Desportos no Brasil, realizado por Lamartine Pereira da Costa (1971), assinalou a necessidade da pesquisa para o avanço da EF e do esporte no Brasil. Com base nesse diagnóstico, o Governo Federal delineou uma nova política para a EF e o esporte no país, que foi direcionada para aprimorar as condições físicas da população em geral e, principalmente, elevar o nível técnico das equipes esportivas nacionais, pois os atletas brasileiros não se destacavam em competições internacionais, em comparação com os atletas oriundos de países que desenvolviam pesquisas relacionadas ao campo esportivo (MAZO, 2000d). Para melhorar o nível científico da EF, e pretensamente o desempenho esportivo do país, o Governo Federal instituiu incentivos à pós-graduação e investimentos em laboratórios ${ }^{1}$ de pesquisa em Medicina e Ciências do Esporte nas Escolas de EF das principais universidades federais (BRACHT, 2013, 1998, MAZO, 2000d).

Apesar de o "fazer científico" ter sido incorporado na arquitetura acadêmica da Educação Física brasileira entre os anos 1970 e 1990, a emergência de um modo de pensar o corpo em movimento mediado por uma racionalidade científica remonta ao século XIX na Europa, período no qual os métodos ginásticos foram sistematizados e sua aplicação em larga escala fundamentada nos pressupostos biomecânicos e fisiológicos desenvolvidos nos rudimentares laboratórios daquele tempo (SOARES, 2013; GÓIS JÚNIOR; SOARES; TERRA, 2015). Esse modo de entender o corpo começa a ganhar visibilidade no Brasil no início do século XIX, com a publicação das obras inaugurais de Fernando de Azevedo, autor que procurou justificar a pertinência da ginástica científica para o projeto de nação que foi posto em marcha naquele momento histórico (FRAGA, 2003; GOELLNER; FRAGA, 2004; GÓIS JÚNIOR, 2015).

Já na segunda metade do século XX no Brasil, mais especificamente nos anos 1960, quando o esporte já havia assumido de vez a importância social, política e econômica outrora conferida à ginástica, começam a surgir no meio acadêmico propostas de cientifização da EF

1 De acordo com Yara Carvalho (2001, p 80), os laboratórios de pesquisa começaram a se efetivar "nos cursos de Educação Física das Universidades Federais de Pernambuco, do Rio de Janeiro e do Rio Grande do Sul, o da Universidade de São Paulo, USP; e Centro de Estudos do Laboratório da Aptidão Física de São Caetano do Sul, não vinculado a uma instituição superior". 
que pretendiam conferir um estatuto epistemológico à área e, por conseguinte, eliminar do horizonte formativo o perfil do professor-treinador dedicado exclusivamente à prática, até então predominante (BETTI, 2005). Ciência da Motricidade Humana, Ciência da Ação Motriz, Ciência do Movimento Humano e, especialmente, Ciências do Esporte buscaram sistematizar, cada uma ao seu modo, um conjunto de pressupostos científicos que intencionavam legitimar a EF em um cenário universitário no qual a pesquisa, especialmente aquela demarcada pelas Ciências Naturais, era (e ainda é) protagonista (LOVISOLO, 1996; BRACHT, 1999, BETTI, 2005, LIMA, 2000a, 2000b).

É importante frisar que a singularidade desse processo de materialização do fazer científico na formação inicial em EF no Brasil não se circunscreveu, e muito menos se constituiu, apenas em torno dos acontecimentos no período demarcado (1970-1990), mas também pela reverberação da racionalidade científica que alavancou a ginástica no início do século XX no Brasil e deu solidez acadêmica às Ciências do Esporte na segunda metade do século XX. Tal como afirma Fraga (2003, p. 103), "a força interpelativa dessas 'velhas' certezas não se impõe pela simples conservação de um discurso tradicional que resiste ao tempo. Pelo contrário, essa tradição se faz presente justamente porque é reinventada, afirmada e cultivada em cada alteridade". Neste estudo ${ }^{2}$, portanto, voltamos nossa atenção para uma pequena alteridade entre tantas passíveis de destaque no período supracitado: a materialização do "fazer científico" na matriz curricular da formação inicial na Escola de Educação Física, Fisioterapia e Dança da Universidade Federal do Rio Grande do Sul (EsEFID/UFRGS)3.

Para tanto, partimos de um achado muito pontual ao longo do processo de análise das grades curriculares dos cursos de EF da EsEFID: a inclusão na matriz curricular de 1987, pela primeira vez em 46 anos de existência da Escola, de disciplinas que continham a palavra pesquisa em seus títulos, especificamente Metodologia da Pesquisa em EF e Seminário de Pesquisa em EF. Cabe destacar que essas disciplinas não tratavam somente do "saber científico", ou seja, de conhecimentos advindos de pesquisas científicas, mas enfocavam também o "fazer científico". Esse detalhe foi percebido com a leitura das súmulas de todas as disciplinas do currículo do curso de EF da Escola do ano de 1987.

As súmulas das outras disciplinas envolviam o estudo de métodos e técnicas de ensino de diversos esportes, de métodos de treinamento físico, das regras de arbitragem dos esportes, das teorias da Educação, da morfologia humana, entre outras. Diferentemente das demais, as súmulas das disciplinas Metodologia da Pesquisa em EF e Seminário de Pesquisa em EF abordavam os principais passos para a realização de pesquisas, a instrumentalização para a execução de investigações científicas. Essas disciplinas enfocavam, portanto, a formação para a pesquisa, a experiência de pesquisa na área da $E F$, ou seja, tratavam dos conhecimentos e habilidades necessários para que o futuro professor de EF pudesse "se fazer cientista" dentro de uma perspectiva teórica mais alinhada à racionalidade biomédica. A partir de 1987 outras disciplinas com o mesmo caráter foram acrescentadas, portanto, é possível pensar que o "fazer científico" ganhou força na formação inicial e se materializou no currículo da Escola4.

\footnotetext{
2 Este estudo é oriundo da Tese de Doutorado intitulada A emergência do "fazer científico" na formação inicial em Educação Física da ESEF/ UFRGS, de autoria de Cibele Biehl Bossle (2014).

3 Em 2015, a instituição passou a se chamar Escola de Educação Física, Fisioterapia e Dança, levando a uma alteração da sigla para EsEFID/ UFRGS, porém nos documentos anteriores aparece a sigla ESEF/UFRGS. Em função dessa alteração, manteremos a sigla ESEF/UFRGS nas citações literais dos documentos utilizados na pesquisa. Nas demais situações em que estivermos nos referindo a EsEFID/UFRGS, doravante, usaremos simplesmente "Escola".

4 Esse aumento do número de disciplinas voltadas ao "fazer científico" pôde ser visualizado através da remontagem das grades curriculares dos cursos de EF desde 1940, ano do início do funcionamento da Escola. A reconstituição dessas grades curriculares foi realizada através de
} 
Esse movimento se torna mais instigante na medida em que analisamos o modelo de formação vigente na Escola até a década de 1980. As disciplinas presentes no currículo daquela época eram essencialmente técnicas, voltadas para o esporte de rendimento e baseadas na ideia de que se "tu sabes fazer, tu vais saber ensinar" (STIGGER, 2010), modelo de formação comumente encontrado nas IES no período anterior a 1980 (DARIDO, 1995). Entretanto, a inserção de disciplinas dirigidas especificamente à formação para a pesquisa na matriz curricular de 1987 parece indicar uma possível mudança de escala no modelo de formação até então instituído na Escola, o que nos permite espreitar na micropolítica da EsEFID o movimento macropolítico de cientifização da formação superior em EF daquele período. O presente estudo problematiza essa mudança e objetiva compreender as condições de possibilidade para a materialização de um tipo específico de "fazer científico" na matriz curricular da formação inicial em EF da UFRGS.

\section{CAMINHOS METODOLÓGICOS}

Para contemplar o objetivo proposto, ao longo de um ano e sete meses realizamos levantamentos nas instalações da EsEFID/UFRGS em busca de documentos que fizessem referência à temática proposta e pudessem compor a empiria. Os levantamentos foram realizados com a devida autorização do diretor da Escola e todos os documentos prospectados, e efetivamente utilizados, são públicos e estão disponíveis a todo tipo de pesquisa.

A análise abrangeu o Livro de Atas da Congregação e do Corpo Docente 1968, Livro de Atas da Congregação ESEF/UFRGS1985-1993, Livro de Atas do Departamento de Ginástica e Recreação (1976-1986), Livro de Atas do Colegiado do Departamento de Desportos ESEF/ UFRGS, Livro de Atas da Comissão de Carreira - COMCAR (1971-1977), ata de fundação do Colégio Brasileiro de Ciências do Esporte $(\mathrm{CBCE})^{5}$, boletins da Associação dos Especializados em Educação Física e Desportos (AEEFD), depoimentos coletados pelo Centro de Memória do Esporte (CEME), documentos da Comissão de Estudos para Implantação do Curso de Mestrado em EF, Regimento do Laboratório de Pesquisa do Exercício (LAPEX) ${ }^{6}$, documentos sobre a incorporação da ESEF pela UFRGS, documentos enviados à Escola por órgãos externos, entre outros. Denominamos esse conjunto de documentos de "marco documental empírico".

Também utilizamos como apoio os Catálogos de Cursos de Graduação encontrados na Biblioteca Central da UFRGS, o marco regulatório educacional brasileiro e a bibliografia disponível sobre a história da Escola (MAZO, 2005, FRAGA et al, 2010, GOELLNER, 2005). Para apreciação dos documentos foi utilizada a análise documental, apoiada nas orientações de Cellard (2012), cuja obra encontra ressonância na teorização arqueológica de Michel Foucault (1997).

A partir dos argumentos de Foucault, Cellard (2012, p. 304) aponta que o pesquisador "desconstrói, tritura o seu material à vontade; depois, procede a uma reconstrução, com vista a responder ao seu questionamento". Em consonância com as orientações de Cellard (2012), após um levantamento preliminar em busca de documentos, realizamos um segundo levanta-

um levantamento das disciplinas oferecidas, a partir de informações disponíveis nos Catálogos de Cursos de Graduação da Biblioteca Central da UFRGS, em documentos do CEME e nas páginas da universidade na internet. A recomposição foi feita por ocasião do "Projeto ESEF 70 anos" (BOSSLE, 2014).

5 O CEME abriga os documentos do CBCE.

6 O LAPEX, instituído em 1973, foi um dos laboratórios de pesquisa financiado pelo Departamento de Educação Física e Desporto do Ministério de Educação e Cultura (DED/MEC), tendo sido o terceiro laboratório criado no Brasil, e inaugurado logo após os da Universidade

Federal do Rio de Janeiro e da Universidade de São Paulo (MAZO, 2000d, CARVALHO, 2001, MAZO; PEREIRA, 2006). 
mento mais detalhado. Todos os documentos foram fotografados e arquivados, somando 723 fotos. Devido à grande quantidade de material recolhido, pareceu-nos necessário organizá-los a fim de facilitar a análise propriamente dita. Para tanto, elaboramos uma tabela geral destacando o título do documento, sua descrição e data, o local onde foi encontrado, quem o emitiu, a quem se dirigia e algumas observações adicionais. Após essa fase, os documentos foram descritos minuciosamente e os trechos considerados mais significativos foram destacados.

Durante a construção das categorias de análise procuramos estabelecer "diálogos" entre os materiais empíricos prospectados, já que, como afirma Cellard (2012), não há como exigir informações adicionais de um documento, é preciso aceitá-lo mesmo em sua incompletude e cotejá-lo com os demais materiais visando o adensamento das informações coletadas.

\section{ANÁLISE E DISCUSSÃO}

A análise empreendida tomou como ponto de partida a significativa influência do LAPEX na materialização do "fazer científico" na formação inicial da EsEFID. Mazo (2000b) aponta o Laboratório como primeiro núcleo de pesquisa da Escola e destaca a contribuição do LAPEX para uma nova maneira de perceber a ciência na EF brasileira, influenciando, inclusive, na mudança do perfil clássico do ensino na Escola. De acordo com Mazo (2000b), antes da implantação do LAPEX não havia tradição de pesquisa na Escola e seu corpo docente privilegiava a formação técnico-esportiva.

Diante das considerações de Mazo (2000b), percebemos que é possível afirmar que o LAPEX funcionou (e ainda funciona) como um aparato não discursivo ${ }^{7}$ que deu vazão ao regime de verdade das Ciências do Esporte e que contribuiu de modo significativo para a materialização do "fazer científico" na matriz curricular dos cursos de Educação Física na UFRGS. A partir daí, passamos a analisar os documentos levantados e, dentre eles, o Boletim da AEEFD n. 8, de 28/04/1975 chamou especialmente nossa atenção. Esse boletim reproduzia a aula inaugural do curso de Técnica Desportiva, proferida pelo então diretor da Escola, Jacintho F. Targa, que destacou os obstáculos que os estudantes encontrariam em sua vida laboral:

Encontrareis muitos obstáculos por parte de pessoas que ainda não compreenderam o valor social e moral dos esportes. Dialogai com eles. Tratai de conquistá-los, pois com certeza vos serão muito úteis para difundir idéias ${ }^{8}$ positivas, uma vez que estejam convencidos de sua validade. É preciso que não cruzeis os braços e vos caleis diante das incompreensões alheias. Tendes que ser combativos e para isso é preciso armar-se dos conhecimentos científicos (TARGA,1975, p. 8).

De acordo com a fala do diretor, os conhecimentos científicos seriam as "armas" para usar no "combate" pela valorização do esporte. O teor do discurso parece tratar especificamente o esporte como a atividade laboral do professor de EF, passando a ideia de que esporte e EF eram entendidos como sinônimos. Nesse sentido, Bracht (2000, p. 60) destaca que "ao contrário da Medicina, a EF ainda tem o agravante de ter que justificar a sua importância social. Daí ela passa a ser confundida com o esporte, que é um fenômeno que lhe empresta prestígio".

Em seguida, o diretor enuncia: "estamos na era científica do esporte" (TARGA, 1975, p. 8). Essa frase parece anunciar um momento calcado pela valorização de conhecimentos científicos, que reflete, na micropolítica da EsEFID, o movimento macropolítico de cientifização

7 No sentido atribuído por Rosa Fischer (1999) ao conceito foucaultiano de dispositivo.

8 Os trechos dos documentos foram reproduzidos conforme a redacão oriainal. 
da formação superior em EF que ocorria naquele período. Seguindo o texto da fala do diretor, é possível perceber quais eram os conhecimentos científicos a serem usados como "armas" no combate à desvalorização do esporte: "Até o fim deste mês estarão em Porto Alegre as maiores autoridades do mundo em pesquisas científicas, participando do Congresso Internacional de Medicina do Esporte" (TARGA, 1975, p. 8).

A partir do exposto acima, é possível pensar que os conhecimentos da "era científica do esporte" eram aqueles ancorados na Medicina do Esporte. Esses conhecimentos ajudariam a valorizar o esporte e, por conseguinte a EF. Assim, "armados" dos conhecimentos da "era científica do esporte", os professores de EF poderiam lutar pela valorização da área e por seu próprio reconhecimento no ambiente de trabalho. A imagem até então desvalorizada aparece com muita força nos documentos encontrados em diferentes setores da EsEFID/UFRGS. Em um depoimento concedido ao CEME, Oliveira, Ferreira e Kroeff (2010) comentam o preconceito que havia em relação ao professor de EF na época em que foram alunas da Escola (período após 1968):

$O$ preconceito era grande. Ainda hoje o professor de EF é considerado como aquela pessoa que não teve capacidade de fazer outro curso. [...] Então vai cursar EF. Também se ouvia, na época, que tinha músculo na cabeça. Enquanto os outros têm cérebro, ele tem músculo (OLIVEIRA, FERREIRA, KROEFF, 2010, p. 13-14).

Essa imagem desprestigiada do professor de EF, um "descerebrado", que tinha somente "músculo na cabeça", também é descrita por Benvenutti (2010). Em depoimento ao CEME, Benvenutti (2010) aborda o período no qual foi aluno da Escola, de 1968 até 19709:

Até na época tinha como até hoje tem [...] aquela imagem do professor e da professora de EF como alguém que a parte intelectual não se desenvolve. Só se desenvolve músculo. [...] antigamente, o profissional de Educação Física não pensava. Até hoje vocês devem passar por isso. Vocês andam por aí e dizem que tem Anatomia, os caras se admiram: 'O quê? Anatomia em EF?'. Tem lá Psicologia, Sociologia' [...] Para quê? Para ensinar os outros a jogar bola, não preciso disso (BENVENUTTI, 2010, p. 08).

A partir do exposto por Benvenutti (2010), é possível pensar que essa imagem do professor de EF que só ensinava a "jogar bola" está ligada ao modelo tradicional-esportivo de formação inicial que se consolidou na década de 1970 e se manteve até a metade da de 1980 (BETTI; BETTI, 1996). Esse modelo enfatizava as disciplinas denominadas "práticas" na formação em EF, especialmente as esportivas (BETTI; BETTI, 1996). Em depoimento concedido ao CEME, Arno Black (2007) ${ }^{10}$ nos dá uma ideia de como era a formação na Escola na década de 1960, quando foi aluno dessa instituição:

[...] nós não éramos treinados para sermos professores, nós éramos treinados para ser atletas e não professor. A gente dominava tudo [...] judô, boxe, ataque e defesa, basquete, vôlei, atletismo, natação, tênis e ginástica [...] Agora ensinar é outra coisa, ensinar. $E$, nós não éramos ensinados para ensinar, nós éramos treinados para repetir, nós éramos repetidores daqueles que nos fizeram (BLACK, 2007, p. 27-28).

O modelo tradicional-esportivo, visando à formação do "professor atleta" (BETTI; BET$\mathrm{TI}, 1996)$ parece ter sido reproduzido pelo corpo docente da Escola. Molina Neto'11 (2008, p. 10) 
comenta que quando era aluno da ESEF/UFRGS os professores eram "pessoas que dominavam muito bem as especificidades das suas disciplinas. Assim, o professor de natação era um exímio nadador, o professor de ginástica era um exímio ginasta". Em depoimento ao CEME, Moraes $^{12}$ (2007) aponta que, no início dos anos 1970, época em que ele foi aluno da Escola, os professores eram pouco reflexivos sobre a sua prática: "Era uma prática do desporto, era uma repetição do desporto, uma repetição do treinador. Se faz, se executa, mas não se reflete sobre ela, sobre qual é a importância dela" (MORAES, 2007, p. 06). Garcia ${ }^{13}$ (2005, p. 10) complementa: "Era raro o professor que tinha o curso de mestrado, então, mais um traço do perfil do professor, poucos deles tinham especialização inclusive, a maioria deles tinha só o curso de graduação".

Mas esse perfil docente foi mudando gradativamente e parece ter acompanhado o movimento macropolítico da EF apontado acima. Molina Neto (2008, p. 13) assinala que a modificação do perfil dos professores acompanhou "as mudanças que a Educação Física foi sofrendo em nível nacional. Então isso tudo que a literatura, da história da Educação Física, da reflexão crítica que foi feita nos anos 80, que se passou, aconteceu aqui na Escola de Educação Física". O perfil do docente da Escola também parece ter sido impactado pela formação stricto sensu adquirida por muitos deles em países da Europa e nos EUA na década de 1980. Molina Neto, Muller e Amaral (2003, p. 76) explicam que esses lugares eram procurados por sua ligação com "uma forte tradição de pesquisa no campo das Ciências Naturais, viés conceptual pelo qual a Educação Física brasileira buscou sua cientificidade".

O docente da EsEFID/UFRGS passa a pensar a pesquisa e a produção de conhecimento também como uma atribuição do professor de EF, o que, de certa forma, também refletia o que estava sendo discutido em nível macro, na área da EF. A produção de conhecimento decorrente de pesquisas realizadas por docentes da Escola passou a conferir status ao professor-pesquisador nessa instituição. As atas da COMCAR começaram a divulgar os artigos e pesquisas realizados por professores da Escola. Esses estudos apresentavam uma forte influência da Medicina, bem como o enfoque na abordagem fisiológica, biomecânica e biométrica, portanto, ligados às Ciências Naturais. Muitos desses professores eram vinculados ao LAPEX, cuja orientação "desde o início foi de desenvolvimento da área biológica da Educação Física com um enfoque particular voltado para a fisiologia do exercício e a medicina do esporte. Essa era a vocação original do LAPEX" (MAZO, 2000c, p. 38).

Vários médicos fizeram parte do corpo docente da Escola. A coordenação do LAPEX ficou sob a responsabilidade de médicos desde sua fundação em 1973 até o fim da década de 1980 (MAZO, 2000b). Os médicos centralizaram a administração e as atividades de pesquisa, sendo que a principal justificativa era de que eles "tinham uma formação científica mais sólida para gerenciar e conduzir a pesquisa realizada no Laboratório" (MAZO, 2000d, p. 94). Para Mazo (2000a), o LAPEX proporcionou suporte técnico-científico para que o Curso de Mestrado em Ciências do Movimento Humano pudesse ser criado em 1989 na Escola. Através da pós-graduação stricto sensu, a Escola alcançaria o prestígio de uma instituição formadora de docentes para o nível superior de ensino e o status de formadora de pesquisadores. Também por meio do mestrado, os professores de EF poderiam "se fazer cientistas", passando a ocupar uma posição melhor na sociedade do que a desvalorizada posição de professor.

12 Além de aluno, Luiz Fernando Ribeiro Moraes foi docente da Escola no período de 1979 até 2010.

13 Cláudio Luiz Garcia iniciou suas atividades como técnico administrativo na EsEFID/UFRGS no início da década de 1970. 
As pesquisas no LAPEX eram realizadas nos padrões da "moda científica da época" (MOLINA NETO, 2008, p. 06), ou seja, de abordagem quantitativa, ligadas a uma racionalidade biomédica. A produção de conhecimentos apoiados em uma racionalidade biomédica, ou seja, no que é considerado científico pela sociedade, agregaria status de pesquisador, de quem "faz ciência", para que os professores de EF pudessem "se fazer cientistas". Os professores da Escola passaram, portanto, de uma formação baseada em conhecimentos técnico-esportivos para uma formação "mais intelectual" ligada ao "fazer científico" de cunho biomédico.

Para tentar escapar do modelo de formação esportivista, a partir da metade da década de 1980, algumas IES

implementaram novas propostas curriculares procurando formar o aluno numa perspectiva mais ampla. Assim, a formação profissional em Educação Física voltou-se da prática das modalidades esportivas para teoria. Na verdade o que houve foi uma valorização do conhecimento científico derivado das ciências mães como base para as tomadas de decisão do profissional (DARIDO, 1995, p. 124).

É possível pensar que essas novas propostas curriculares acompanharam as discussões que estavam acontecendo entre intelectuais da área da EF brasileira, que resultaram na Resolução CFE n. 3/1987 (AZEVEDO; MALINA, 2004; FRAGA, et al, 2010, PAIVA; ANDRADE FILHO; FIGUEIREDO, 2006). O ponto mais emblemático da Resolução CFE n. 3/1987 foi a instituição da divisão do curso de EF em bacharelado e licenciatura. Souza Neto et al (2004, p. 124) apontam que, embora a justificativa para a criação do bacharelado (e a manutenção da licenciatura) fosse o mercado de trabalho, "o que de fato estava em jogo era a introdução de um novo modelo curricular, denominado de "técnico-científico", como proposta de superação de um currículo centrado mais nos conteúdos gímnico-desportivos". Silva et al $(2009$, p. 08) apontam que é possível perceber no processo de fragmentação da formação em EF "o reforço e a consolidação de um discurso cientificista, com fortes marcas biomédicas". Carmo (1988) destaca que ao bacharel caberia a pesquisa e que o currículo dos cursos de EF, mesmo nas áreas pedagógicas e esportivas, precisaria apresentar aspectos formativos científicos mediante a possibilidade de conhecer e desenvolver pesquisas. 0 bacharelado seria, então, o curso formador de pesquisadores na área da EF.

Essas tensões e disputas em relação à formação em EF foram sendo transportadas também para o currículo de ensino superior em EF da EsEFID/UFRGS. Mesmo com a possibilidade de instituir o bacharelado, a comunidade da Escola optou por manter somente o curso de licenciatura em caráter generalista e implantou a sua própria alteração curricular em 1987 (FRAGA et al, 2010). A Escola não incluiu o "bacharel pesquisador" nas alterações curriculares de 1987, mas acrescentou as duas disciplinas do "fazer científico" mencionadas acima, em caráter opcional, na formação inicial em EF.

A formação do "professor atleta" perdeu força no novo currículo. Houve uma desvalorização progressiva das disciplinas práticas, ditas acríticas e não científicas. Portanto, o "saber fazer para ensinar" (DARIDO, 1995, p. 124) foi paulatinamente cedendo espaço para o "fazer científico" no currículo da Escola. É importante destacar que o "fazer científico" foi ganhando força e espaço a ponto de se manter no currículo da Escola e apresentar um considerável aumento no número de disciplinas desde a sua materialização na matriz curricular do ano de $1987^{14}$. Este fato demonstra que, dentre todas as opções disponíveis, os conhecimentos 
relacionados ao "fazer científico" foram selecionados em detrimento de outros, considerados menos importantes.

\section{CONSIDERAÇÕES FINAIS}

A inclusão em 1987 de duas disciplinas diretamente ligadas à pesquisa foi um dos tantos acontecimentos que nos permitiram visualizar o processo de materialização do "fazer científico" na matriz curricular do curso de EF na EsEFID/UFRGS. Entre os vários acontecimentos que levaram a uma mudança de escala no modelo de formação até então vigente na Escola, e por meio do qual foi possível espreitar o movimento macropolítico de cientifização da formação superior em EF daquele período, um mereceu destaque: o esforço pelo reconhecimento da cientificidade da EF que viria a se tornar possível com a eliminação do perfil do professor-treinador do horizonte formativo da área e o investimento na formação de um professor com perfil de pesquisador. Tal movimento, captado no "marco documental empírico" do presente estudo, também é destacado na literatura que trata especificamente deste tema (BETTI; BETTI, 1996, LOVISOLO, 1996, BRACHT, 1999, LIMA, 2000a, 2000b, BETTI, 2005), portanto, não diz respeito exclusivamente à EsEFID, mas à EF brasileira como um todo. Esse movimento micropolítico na Escola não destoava do clamor pela cientifização que procurava dar solidez acadêmica à EF entre os anos 1970 e 1990. Preocupações de ordem epistemológica, como a produção do conhecimento e o estatuto científico, permearam um intenso debate na área e a "indefinição epistemológica" da EF passou a ser o sintoma de uma crise de identidade (LIMA, 2000a). Dada a importância e o status da ciência na sociedade, e particularmente no meio acadêmico, a EF passou a buscar como meta "tornar-se ela própria uma ciência" (BRACHT, 1999, p. 31).

Para Lima (2000b, p. 73), a "busca da cientificidade da Educação Física apoia-se na valorização social da Ciência: a crença de que a Educação Física alcançará a sua legitimidade acadêmica e social, revestindo-se de cientificidade". A valorização da EF passa pela cientifização da EF, pois o discurso da ciência tem status de verdade na sociedade contemporânea. O pesquisador que "faz ciência" é mais valorizado em nossa sociedade do que o docente, especialmente o de EF. Através da cientifização, o professor de EF poderia superar a imagem desvalorizada daquele professor-prático que só ensinava os alunos a jogar bola, "que tinha músculo na cabeça" (OLIVEIRA, FERREIRA, KROEFF, 2010, p. 13), e adquirir status de profissional que não apenas se vale dos conhecimentos científicos, mas tem capacidade e legitimidade para "fazer ciência".

A materialização do "fazer científico" no currículo de 1987 da Escola produziu e ao mesmo tempo foi produzida pela cientifização da EF. Um movimento com características específicas, demarcado pelo declínio de um modelo técnico-esportivo e pela assunção de uma racionalidade biomédica no currículo da Escola. Porém, a racionalidade biomédica que perpassou e legitimou o modo de ser professor-pesquisador da Escola também apresentava a singularidade de estar ligada ao esporte. Autorizamo-nos, então, a chamar essa composição de "racionalidade biomédica desportiva", a qual pode ser vislumbrada na expressão "estamos na era científica do esporte", pronunciada pelo diretor da Escola, Jacintho F. Targa, por ocasião da aula inaugural do curso de Técnica Desportiva do ano de 1975.

Cabe enfatizar que este estudo apontou as condições de possibilidade para a materialização de um "fazer científico" assentado em uma racionalidade biomédica desportiva no cur-

"fazer científico" na matriz curricular da ESEF/UFRGS" contido na tese de doutorado de Bossle (2014). 
rículo do curso de EF da UFRGS. Essa seria, na visão daqueles que deixaram seus registros nos documentos acessados, uma "arma" potente para combater o que Benvenutti (2010, p. 20) denomina de "menos-valia da Educação Física". Amparados na racionalidade biomédica desportiva, os professores de EF poderiam lutar pela mudança da imagem do profissional "prático" e acrítico para o status de professor-pesquisador. Porém, é preciso destacar que esse processo de materialização do "fazer científico" captado por meio da análise do marco documental empírico que compôs o presente estudo não é um acontecimento circunscrito àquele tempo àquela instituição especificamente, mas sim um eco das proposições que vieram constituindo a EF como um campo acadêmico, e a EsEFID/UFRGS como uma importante referência na formação de professores de EF no Brasil. A análise empreendida permitiu-nos, portanto, visualizar na micropolítica de uma instituição específica o movimento de cientifização que balizou (e ainda baliza) a macropolítica na área da EF.

\section{REFERÊNCIAS}

AZEVEDO, Ângela Celeste Barreto de; MALINA, André. Memória do currículo de formação profissional em educação física no Brasil. Revista Brasileira de Ciências do Esporte, v. 25, n. 2, p. 129-142, jan. 2004.

BENVENUTTI, Edson. Edson Benvenutti: depoimento, 2010. Porto Alegre: Centro de Memória do Esporte - ESEF/UFRGS, 2010. Disponível em: <http://www.lume.ufrgs.br/bitstream/handle/123456789/111/000852823.pdf?sequence=1. >. Acesso em: 4 jul. 2016.

BETTI, Mauro. Educação física como prática científica e prática pedagógica: reflexão a luz da filosofia da ciência. Revista Brasileira de Educação Física e Esportes, v. 19, n. 3, p.183-97, jul./set. 2005.

BETTI, Irene C. Rangel; BETTI, Mauro. Novas perspectivas na formação profissional em Educação Física. Motriz, v. 2, n. 1, p. 10-15, jun. 1996.

BLACK, Arno. Arno Black: depoimento, 2005. Porto Alegre: Centro de Memória do Esporte - ESEF/ UFRGS, 2007. Disponível em: <http://www.lume.ufrgs.br/bitstream/handle/10183/50037/000729657. pdf? sequence=1>. Acesso em: 4 jul. 2016.

BOSSLE, Cibele Biehl. A emergência do "fazer científico" na formação inicial em Educação Física da ESEF/UFRGS. 269 f. 2014. Dissertação (Mestrado) - Escola de Educação Física, Fisioterapia e Dança, Universidade Federal do Rio Grande do Sul, Porto Alegre, 2014.

BOTELHO, Rafael Guimarães; OLIVEIRA, Cristina da Cruz de. Iniciação científica e formação de professores na Universidade do Estado do Rio de Janeiro: a produção na área da Educação Física.

Revista Brasileira de Educação Física, Esporte, Lazer e Dança, v. 1, n. 2, p. 34-52, jun. 2006.

BRACHT, Valter. Epistemologia, Ensino e Crítica: desafios contemporâneos. In: GOMES, Ivan Marcelo; ALMEIDA, Felipe Quintão de; VELOZO, Emerson Luís. Epistemologia, ensino e crítica: desafios contemporâneos para a Educação Física. Nova Petrópolis: Nova Harmonia, 2013. p. 19-30.

BRACHT, Valter. Educação Física \& Ciência: cenas de um casamento (in)feliz. Revista Brasileira de Ciências do Esporte, v. 22, n. 1, p. 53-63, 2000.

BRACHT, Valter. Educação Física \& Ciência: cenas de um casamento (in)feliz. ljuí: Ed. UNIJUÍ, 1999. BRACHT, Valter. Um pouco de história para fazer história: 20 anos do CBCE. Revista Brasileira de Ciências do Esporte, Número Especial 20 anos de CBCE, p. 12-18, set. 1998.

CARMO, Apolônio Abadio do. Licenciado e/ou bacharelado: alguns entendimentos possíveis. Motrivivência, Florianópolis, n. 1, p. 73-76, dez.,1988.

CARVALHO, Yara Maria de. 0 mito da atividade física e saúde. São Paulo: Huicitec, 2001. 
CELLARD, André. A análise documental. In: POUPART, Jean et al. A pesquisa qualitativa: enfoques epistemológicos e metodológicos. Petrópolis, RJ: Vozes, 2012. p. 295-316.

COSTA, Lamartine Pereira da. Diagnóstico de educação e desportos no Brasil. Rio de Janeiro: FENAME, 1971.

DARIDO, Suraya Cristina. Teoria, prática e reflexão na formação profissional em Educação Física. Motriz, v. 1, n. 2, p. 124-128, dez. 1995.

FISCHER, Rosa Maria Bueno. Foucault e o desejável conhecimento do sujeito. Revista Educação e Realidade, v. 1, n. 24, p. 39-59, jan./jun. 1999.

FOUCAULT, Michel. A Arqueologia do saber. Rio de Janeiro: Forense Universitária, 1997.

FRAGA, Alex Branco. Espectros de Antinoüs: educação do físico e governo dos corpos no Brasil. Iberoamericana, v. 3, n. 10, p. 103-112, 2003.

FRAGA, Alex Branco et al. Alterações curriculares de uma escola septuagenária: um estudo sobre as grades dos cursos de formação superior em Educação Física da ESEF/UFRGS. Movimento, Porto Alegre, p. 61-95, 2010. Edição Especial.

GARCIA, Cláudio Luiz. Cláudio Luiz Garcia: depoimento, 2004. Porto Alegre: Centro de Memória do Esporte - ESEF/UFRGS, 2005. Disponível em: <http://www.lume.ufrgs.br/bitstream/handle/10183/50013/000729046.pdf? sequence=1> Acesso em: 4 jul. 2016.

GOELLNER, Silvana Vilodre et al. ESEF 65 anos: entre memórias e histórias. Movimento, Porto Alegre, v. 11, n. 3, p. 201-218, set./dez. 2005.

GOELLNER, Silvana Vilodre; FRAGA, Alex Branco. A inominável Sandwina e as obreiras da vida: silêncios e incentivos nas obras inaugurais de Fernando de Azevedo. Revista Brasileira de Ciências do Esporte, v. 25, n. 2, p. 71-84, 2004.

GÓIS JUNIOR, Edivaldo. Georges Demeny e Fernando de Azevedo: uma ginástica científica e sem excessos (Brasil, França, 1900-1930). Revista Brasileira de Ciências do Esporte, v. 37, p. 144-150, 2015. GÓIS JUNIOR, Edivaldo; SOARES, Carmen Lúcia; TERRA, Vinícius Demarchi Silva. Corpo-máquina: diálogos entre discursos científicos e a ginástica. Movimento, v. 21, n. 4, p. 973-984, 2015.

LIMA, Homero Luis Alves de. Pensamento epistemológico da educação física brasileira: das controvérsias acerca do estatuto científico. Revista Brasileira de Ciências do Esporte, v. 21 n. 2, p. 95102, jan./maio, 2000a.

LIMA, Homero Luis Alves de. Epistemologia, relativismo e educação física. Revista Brasileira de Ciências do Esporte, v.2 1, n. 1, p. 65-77, set., 2000b.

LOVISOLO, Hugo Rodolfo. Hegemonia e legitimidade nas ciências do esporte. Motus Corporis, v. 3 , n. 2, p. 51-72, 1996.

LOVISOLO, Hugo Rodolfo. A política de pesquisa e mediocridade possível. Revista Brasileira de Ciências do Esporte, v. 24, n. 2, p. 97-114, 2003.

MAZO, Janice Zarpellon. Memórias da Escola Superior de Educação Física da Universidade Federal do Rio Grande do Sul (ESEF/UFRGS): um estudo do período de sua fundação até a federalização (1940-1969). Movimento, v. 11, n. 1, p. 143-167, jan./abr. 2005.

MAZO, Janice Zarpellon. Laboratório de pesquisa do Exercício da ESEF/UFRGS: apontamentos para uma história dos seus 25 anos. Movimento, Ed. Esp., p. 1-96, maio, 2000a.

MAZO, Janice Zarpellon. A criação do Laboratório de Pesquisa do Exercício da Escola de Educação Física da UFRGS. Movimento, Ed. Esp., p. 11-22, maio, 2000b.

MAZO, Janice Zarpellon. Depoimentos dos coordenadores e diretores do LAPEX. Movimento, Ed. Esp. p. 23-67, maio, 2000c. 
MAZO, Janice Zarpellon. Os Laboratórios de Pesquisa do Exercício: algumas considerações. Movimento, Ed. Esp., p. 8-10, maio, 2000d.

MAZO, Janice Zarpellon; PEREIRA Priscilla Goulart. Escola de Educação Física da Universidade Federal do Rio Grande do Sul - ESEF-UFRGS. In: DA COSTA, Lamartine (Org.). Atlas do esporte no Brasil. Rio de Janeiro: CONFEF, 2006. Disponível em: <http://www. atlasesportebrasil.org.br/textos/348.pdf >. Acesso em: 4 jul. 2016.

MOLINA NETO, Vicente. Vicente Molina Neto: depoimento, 2005. Porto Alegre: Centro de Memória do Esporte - ESEF/UFRGS, 2008. Disponível em: <http://www.lume.ufrgs.br/bitstream/handle/10183/50044/000729670.pdf?sequence=1>. Acesso em: 4 jul. 2016.

MOLINA NETO, Vicente; MULLER, Márcio Amaro; AMARAL, Luciano do. O Programa de Pós-Graduação em Ciências do Movimento Humano da ESEF/UFRGS: a visão dos estudantes sobre o seu processo de formação profissional. Revista Brasileira de Ciências do Esporte, v. 24, n. 2, p. 75-96, jan., 2003.

MORAES, Luiz Fernando Ribeiro. Luiz Fernando Ribeiro Moraes: depoimento, 2004. Porto Alegre: Centro de Memória do Esporte - ESEF/UFRGS, 2007. Disponível em: <http://www.lume.ufrgs.br/bitstream/handle/10183/50014/000729047.pdf? sequence=1>. Acesso em: 4 jul. 2016.

OLIVEIRA, Vera Lúcia da Silva; FERREIRA, Vera Maria; KROEFF, Maria Alice Garcia. Vera Oliveira, Vera Ferreira e Maria Kroeff: depoimento, 2010. Porto Alegre: Centro de Memória do Esporte - ESEF/UFRGS, 2010. Disponível em: <http://www.lume.ufrgs.br/bitstream/handle/123456789/196/000852699.pdf?sequence=1>. Acesso em: 4 jul. 2016.

PAIVA, Fernanda Simone Lopes de; ANDRADE FILHO, Nelson Figueiredo; FIGUEIREDO; Zenólia Cristina Campos. Formação inicial e currículo no CEFD/UFES. Pensar a Prática, v. 9, n. 2, p. 213-230, jul./dez. 2006.

SILVA, Ana Márcia et al. A formação profissional em Educação Física e o processo político social. Pensar a Prática, v. 12, n. 2, p. 1-16, ago. 2009.

SOARES, Carmen Lúcia. Imagens da educação no corpo. 4. ed. Campinas: Autores Associados, 2013. v. 1.

SOUZA NETO, Samuel de et al. A formação do profissional de educação física no Brasil: uma história sob a perspectiva da legislação federal no século XX. Revista Brasileira de Ciências do Esporte, v. 25, n. 2, p. 113-128, 2004.

STIGGER, Marco Paulo. Marco Stigger: depoimento, 2010. Porto Alegre: Centro de Memória do Esporte - ESEF/UFRGS, 2010. Disponível em: <http://www.lume.ufrgs.br/bitstream/handle/10183/50076/000758223.pdf?sequence=1>. Acesso em: 4 jul. 2016.

TARGA, Jacintho F. Alguns Aspectos da problemática da educação física na UFRGS: aula inaugural do curso de técnica desportiva. Boletim da Associação dos Especializados em Educação Física e Desportos, n. 8, p. 08, 28 abr., 1975. Disponível no acervo físico do Centro de Memória do Esporte da ESEFID/UFRGS.

VAZ, Alexandre Fernandez. Sobre a relação ensino-pesquisa na formação inicial em Educação Física. Motrivivência, v. 20, p. 76-90, 2008. 